Ein Fall, der wenigstens theilweise hierher gehören könnte, würde auch die von Audubon hervorgehobene, auffallende Zunahme des Wanderfalken im nördlichen Amerika sein. (Vergl. „Journ. f. Orn.", Jahrg. 1855, S. 22-23.) Indess mag allerdings bei ihm der Hauptgrund ein anderer sein. Ich glaube nämlich, dass Hr. v. Homeyer in der That richtig gerathen hat, wenn er („Journ." 1855, S. 439 ,) dieses immer zahlreichere Erscheinen desselben dort hauptsächlich als durch die rasch zunehmenden Waldrodungen veranlasst ansieht: weil diese einem so rasch fliegenden und meist immer auf dem Freien jagenden Raubvogel hierzu nun ein weit freieres Feld gewähren, als früher. Denn offenbar liebt er weniger den Wald an sich, als vielmehr nur als Nistund Schutzplatz, um sich nach dem Jagen darin zu verbergen. Daher findet er sich, nach Hrn. v. Nordmann, sogar auf den russischen Steppen, wiewohl im Sommer seltener, als den Herbst und Winter hindurch; und Hr. v. Middendorff hat ihn ja selbst in Livland, wo es doch wahrlich an Waldung nicht fehlt, meistens auf der Erde nistend angetroffen. Wald- oder Baumvogel ist er daher nach Umständen bald eben so wenig, wie die Adler, bald eben so sehr, wie sie.

Berlin, den 23. Februar 1856.

Gloger.

Zur Paarmugsgeschichte der Vägel kann ich behaupten, dass nicht alle Vögel jeden Sommer in einem gepaarten Zustande sich befinden, und dass zweitens besonders diejenigen Vögel, welche ein hohes Alter erreichen, im zweiten Sommer ihres Lebens, also als einjährige Vögel, sich noch nicht zu paaren scheinen. Diese Behauptungen sind auf gemachte Erfahrungen begründet.

In Bezug auf die zuerst aufgestellte Behauptung führe ich das folgende Factum an: Ein Schwalben-Paar von Hirundo urbica baute sich unter dem Dache meiner Scheune, meiner Wohnstube gegenüber, ein Nest und nahm das Material nach einem Statt gehabten Regen sogleich auf dem Hofraume auf. Es war nur noch der Eingang des Nestes etwas zu verengern, als das Männchen bei der Bereitung des Materials schon in den Morgenstunden von einer Katze gefangen wurde. Da ich zufällig aus dem Fenster meiner Stube den Fang ansah, so nahm ich der Katze schnell den Vogel ab; er war jedoch schon todt. Das Weibchen sass nun diesen und den folgenden Tag fast stets im Neste und liess allerhand leise Töne vernehmen. Am dritten Tage hatte sich wieder ein Männchen zu ihm gesellt; sie vollendeten nun das Nest und brüteten Junge aus. Das neu hinzugekommene Männchen musste sich also noch ungepaart, oder verwittwet und ohne Nest, vorgefunden haben. 
Ein anderer und in mancher Hinsicht noch interessanterer Fall bestätigt gleichfalls meine obige Behauptung: In der Asthöhle eines Apfelbaumes meines Gartens brütete ein Meisen-Paar der Spiegel- oder Kohlmeise, Parus major. Ihr Nest befand sich gerade in meiner Augenlinie, so dass ich bisweilen hineinschaute. Das Nest enthielt 7 Junge, welche schon Federn bekamen. Als ich eines Tages in den Morgenstunden im Garten stand und aus geringer Entfernung beobachtete, wie Männchen und Weibchen wechselseitig ihre Jungen fleissig fütterten, fiel im Garten des Nachbars, welcher einen Bienenstand hatte, ein Schuss; das Weibchen kam geflogen, setzte sich auf den Knoten am Astloçhe, fiel aber auch in dem Augenblicke todt zur Erde. Gegen Abend desselben Tages hatte das Männchen sich schon wieder ein anderes Weibchen zugesellt, welches mit eben dem Fleisse, wie die rechte Mutter, die Jungen fütterte und aufziehen half.

Was nun die zweite oben aufgestellte Behauptung anbetrifft, dass nämlich besonders die, ein hohes Alter erreichenden Vögel sich wahrscheinlich nicht gleich im zweiten Sommer ihres Lebens oder als einjährige Vögel paaren, so glaube ich dafür Folgendes anführen zu können :

Falco milvus, der rothbraune Milan, horstet in meiner früheren Gegend, in den bergigen Eichenwaldungen des Vorharzes, nicht; und wenn der Frühjahrszug vorüber ist, erblickt man dennoch während des Sommers, und ehe es neue Junge geben kann, einzelne Exemplare daselbst die Luft durchstreichen. Von diesen habe ich auf der benachbarten Krähenhütte eines Freundes mehrere geschossen, aber immer gefunden, dass es entschieden junge Vögel des vorigen Sommers waren; denn sie trugen alle das Jugendkleid ihres ersten Herbstes. Besonders zeigten sie die Kopf- oder Scheitelfedern, welche der junge Vogel im ersten Herbste auf seine Wanderung mitnimmt, so wie auch überhaupt das blässere Gefieder der Jungen des vorigen Herbstes; auch ihre Augenringe und Fänge waren blässer gefärbt.

Eine gleiche Bemerkung habe ich in Hinsicht des Falco Nisus gemacht.

Bei den Störchen, glaube ich, findet es wohl gleichfalls Statt, dass sie sich nicht schon im zweiten Sommer paaren und mag diess mit ein Grund ihrer geringen Vermehrung sein. Man sieht sie im Sommer, in der Zeit, wo sie schon ihre Jungen füttern, auch einzeln in den hiesigen Feldern, wo es wenig Nahrung für sie giebt, umherstreichen, wiewohl die nächsten erst einige Stunden von hier ihre Brutorte haben. Ganz besonders aber brachte mich ein Zug von 41 Stück auf diesen 
Gedanken, da dieselben als horstende Vögel in dortiger Gegend nur aus weiter Ferne zusammenzubringen gewesen wären. Dieser Flug kam am 25. Mai, also lange nach der Frühjahr-Zugzeit, in ordentlich geschaartem Zuge aus Süden heran und liess sich in hiesiger Feldflur auf einige Zeit zur Aesung nieder. Waren alle diese Störche vielleicht erst einjährige Vögel, und daher für dieses Jahr noch ungepaart und ohne Brutstätte? Möchte doch von Waidmännern und sonstigen Naturfreunden auf den angeführten Punkt, dass Störche und Raubvögel sich nicht schon im zweiten Sommer paaren, geachtet und so die hier ausgesprochene Vermuthung bestätigt werden. Bei den Falkenarten dient, zur Beurtheilung des Alters, das Federkleid als Richtschnur und diess vorzüglich bei Falco Milvus, Nisus, F. palumbarius und peregrinus.

Halle.

Rimrod, Pastor emer.

\section{Einige Bemerkungen}

über Hrn. Hansmann's Aufsatz: „die Zeichnung der Kehle steht bei den Vögeln gewöhnlich mit ihrem Gesange in keiner Beziehung."

Herr Hansmann in Berlin hat in diesem Journale (Jahrg. 1855, No. 16, S. 348-351,) meinen Aufsatz in der Naumannia, Jahrg. 1855, 4. Quartal, „die Farbe der Kehle steht bei den Vögeln mit ihrem Gesange in Beziehung", einer Kritik unterzogen und mir den Fehdehandschuh hingeworfen. Ich hebe ihn mit Vergnügen auf und trete mit dem, mir lieb gewordenen Gegner in die Schranken, um eine Lanze mit ihm zu brechen, wodurch dann der Streit beendigt und die Verständigung herbeigeführt werden wird; denn ich liebe es nicht, eine Fehde länger fortzusetzen, als unumgänglich nothwendig ist. Ich habe den Fehler begangen, dass ich den Satz zu allgemein hingestellt habe, denn es ist mir nie eingefallen, zu behaupten, dass die Vögel um so schöner sängen, je herrlicher ihre Kehle gefärbt sei. Eine solche Albernheit wird mir Niemand zutrauen; sonst hätte ich ja die Kolibris als die vorzüglichsten Sänger aufführen müssen, weil die Kehle vieler von ihnen am herrlichsten gefärbt ist. Wenn aber Herr Hansmann behauptet: „die Zeichnung der Kehle steht bei den Vögeln gewöhnlich mit ihrem Gesange in keiner Beziehung:" so hat er ganz Unrecht, wie aus Folgendem deutlich werden wird.

Wir kommen zuerst auf die Schwalben. Alle zu Cecropis gehörenden Arten, als Cecropis rustica, rufula, ruffrons, filicauda, orientalis, americana etc., haben unter den Schwalben die am Lebhaftesten gefärbte Kehle und singen auch am Schönsten, was Hr. Hans- 